\section{Ribonuclease Protection Assay Streamlined for High Throughput with RNA in Formamide and Single-Step RNase Inactivation}

\section{BioTechniques 32:502-506 (March 2002)}

The ribonuclease protection assay (RPA) is a powerful technique for measuring gene expression, but it is laborious, especially when large numbers of samples are analyzed. We developed a streamlined RPA protocol that eliminates two of the most tedious steps in the standard procedure. First, the need for re-precipitation of sample RNA before hybridization with labeled probes is eliminated by resuspending RNA pellets in formamide at the final stage of RNA extraction from cells or tissues. Second, RNase A/T1 inactivation is accomplished by proteinase $\mathrm{K}$ digestion followed directly by ethanol/salt precipitation. We show that omitting phenol:chloroform extraction causes only a minimal reduction in sensitivity compared to the standard procedure, without affecting reliability.

In standard RPA protocols $(4,11)$, RNA samples stored in aqueous solution must be re-precipitated before use because hybridization is carried out in a buffer with a high concentration of formamide (typically 80\%). Chomczynski (2) demonstrated that storing in formamide protects RNA from degradation. To our knowledge, it has not been appreciated previously that storing RNA in formamide is particularly advantageous for RPA analysis. Storing RNA in formamide allows the RNA to be added directly to a probe/buffer solution. This saves time and effort and avoids a potential source of sample loss. Re-precipitation of RNA can also be avoided by using an aqueous hybridization procedure (7), but this requires modified salt and temperature conditions. In contrast, the use of RNA in formamide is applicable, without any change in conditions previously optimized for particular probe sets, to any version of the RPA that utilizes highformamide hybridization.
Our protocol also eliminates the phenol:chloroform extraction step of the standard RPA. Although other alternatives to phenol:chloroform extraction are available, each has potential disadvantages. Using $\beta$-mercaptoethanolcontaining solutions for inactivation/ precipitation $(1,5,6)$ requires a fume hood and produces combined chemical and radioactive hazardous waste, which increases disposal costs. $\beta$-mercaptoethanol can be omitted if RNase T2, rather than the standard RNase A/T1 mixture, is used (10), but switching to RNase T2 may require re-optimization of previously established conditions. Ambion (Austin, TX, USA) produces a reagent that inactivates RNases $\mathrm{A} / \mathrm{T} 1$ and precipitates RNA in a single step, but it is expensive.

RNA was obtained from the lungs of mice $4 \mathrm{~h}$ after intravenous injection of $50 \mu \mathrm{g}$ LPS (9). Total RNA was extracted using the acid phenol-guanidine isothiocyanate method (3), except that RNA pellets were resuspended in formamide (2) after the final ethanol precipitation, and stored at $-80^{\circ} \mathrm{C}$. Absorbances at $260 \mathrm{~nm}$ were measured on aliquots diluted $1: 250$ in $2 \mathrm{mM}$ $\mathrm{Na}_{2} \mathrm{HPO}_{4}$ buffer at $\mathrm{pH} 8.5$ (15) or in water. Glycogen, Glycoblue ${ }^{\mathrm{TM}}$, proteinase K, RNase T1, and RNase Inactivation/Precipitation Solution III were purchased from Ambion. RNase A was from Sigma (St. Louis, MO, USA). Probe templates were linearized plasmids treated with proteinase $\mathrm{K}$, followed by phenol:chloroform extraction. Probes for murine IL- $1 \beta$ and the chemokines LIX (12), ITAC (14), crg2/IP10 (13), and Lungkine (8) were used together with a probe for the ribosomal protein S2 mRNA (9) as a loading control. The sizes and specific cDNA regions in the probes were: LIX, 354 nucleotides (135-488 of GenBank ${ }^{\circledR}$ accession no. U27267); IL-1 $\beta$, 239 nucleotides (453-691 of M15131); ITAC, 209 nucleotides (360-568 of AF179872); IP10/crg2, 143 nucleotides (46-188 of M86829); Lungkine, 114 nucleotides (238-351 of AF082859); and S2, 102 nucleotides (191-292 of AF283559).

${ }^{32} \mathrm{P}$-labeled riboprobes, generated by in vitro transcription $(4,11)$, were dissolved in $20 \mu \mathrm{L}$ formamide after precipitation. Alternatively, the probes could be purified using a spin column and dried under vacuum before resuspension in formamide. A probe master mixture for $N$ samples was prepared by combining $N \times 10^{5}-10^{6} \mathrm{cpm}$ riboprobe, $N \times 2 \mu \mathrm{L} 5 \times$ hybridization buffer $(200$ mM PIPES, pH 6.4, 2 M NaCl, 5 mM EDTA), and formamide in a total volume of $N \times 4 \mu \mathrm{L}$. Each RNA sample (in formamide) was combined with probe master mixture $(4 \mu \mathrm{L})$ and formamide, in a total volume of $10 \mu \mathrm{L}$. The samples were heated in a water bath at $89^{\circ} \mathrm{C}-92^{\circ} \mathrm{C}$ for $3 \mathrm{~min}$ and then transferred to a $42^{\circ} \mathrm{C}$ incubator for overnight hybridization. The next day, $150 \mu \mathrm{L}$ RNase digestion solution was added, and the tubes were incubated at $37^{\circ} \mathrm{C}$ for $30 \mathrm{~min}$. RNase digestion solution was prepared by diluting a $50 \times$ RNase A/T1 stock solution $(25 \mu \mathrm{g} / \mathrm{mL}$ RNase $\mathrm{A}$ and $5000 \mathrm{U} / \mathrm{mL}$ RNase $\mathrm{T} 1$ in $50 \%$ glycerol) to $1 \times$ in digestion buffer (10 $\mathrm{mM}$ Tris-Cl, pH 7.5, $300 \mathrm{mM} \mathrm{NaCl,} 5$ mM EDTA).

RNase inactivation mixture was prepared by combining $N \times 10 \mu \mathrm{L} 10 \%$ SDS, $N \times 5 \mu \mathrm{L} 10 \mathrm{mg} / \mathrm{mL}$ proteinase K, and $N \times 1 \mu \mathrm{L} 5 \mathrm{mg} / \mathrm{mL}$ glycogen. Optionally, $N \times 0.5 \mu \mathrm{L}$ Glycoblue was added to enhance the visibility of the pellet. After the addition of $16 \mu \mathrm{L}$ RNase inactivation mixture $(16.5 \mu \mathrm{L}$ with Glycoblue), the sample tubes were incubated at $37^{\circ} \mathrm{C}$ for $30 \mathrm{~min}$. The protected fragments were precipitated with $518 \mu \mathrm{L}$ ethanol/salt mixture (500 volumes ethanol plus 18 volumes $5 \mathrm{M}$ ammonium acetate). After incubation for $30 \mathrm{~min}$ at $-20^{\circ} \mathrm{C}$ and centrifugation at $14000 \times g$ for $15 \mathrm{~min}$ at $4^{\circ} \mathrm{C}$, the pellets were dissolved in $5 \mu \mathrm{L}$ gel loading buffer $(95 \%$ formamide, $0.025 \%$ xylene cyanol, $0.025 \%$ bromophenol blue, $18 \mathrm{mM}$ EDTA, $0.025 \%$ SDS), and briefly vortex mixed. The samples were heated at $89^{\circ} \mathrm{C}-92^{\circ} \mathrm{C}$ for $3 \mathrm{~min}$ and then placed on ice before loading on a $5 \%$ polyacrylamide, $8 \mathrm{M}$ urea gel. Electrophoresis was performed at 35 $\mathrm{mA}$ for $2 \mathrm{~h}$. After drying, the gel was exposed to a phosphor plate overnight and then analyzed using a PhosphorImager $^{\mathrm{TM}}$ (Molecular Dynamics, Sunnyvale, CA, USA). For each probe, the result for each sample lane in a single experiment was scaled so that the mean value for the standard treatment was equal to 100 . To evaluate differences 
among treatment groups, normalized data for all probes were analyzed by ANOVA using StatView 5.0.1 (SAS Institute, Cary, NC, USA). For comparisons significant by ANOVA at $P$ $<0.05$, differences between methods were evaluated using Fisher's protected least significant difference (PLSD) test.

To assess the effect of omitting the phenol:chloroform extraction step, replicate samples of RNA in formamide were hybridized with riboprobe and incubated with RNases A and T1 as described above. The samples were then subjected to three different RNase inactivation/precipitation procedures: $(i)$ our streamlined procedure, as described above; (ii) the standard procedure, in which proteinase $\mathrm{K}$ digestion in SDS/ glycogen buffer, as described above, was followed by phenol:chloroform extraction before ethanol/salt precipitation; and (iii) the addition of $225 \mu \mathrm{L} \mathrm{Am-}$ bion's Inactivation/Precipitation reagent.

The experiment was performed three times, with similar results (Figure 1).

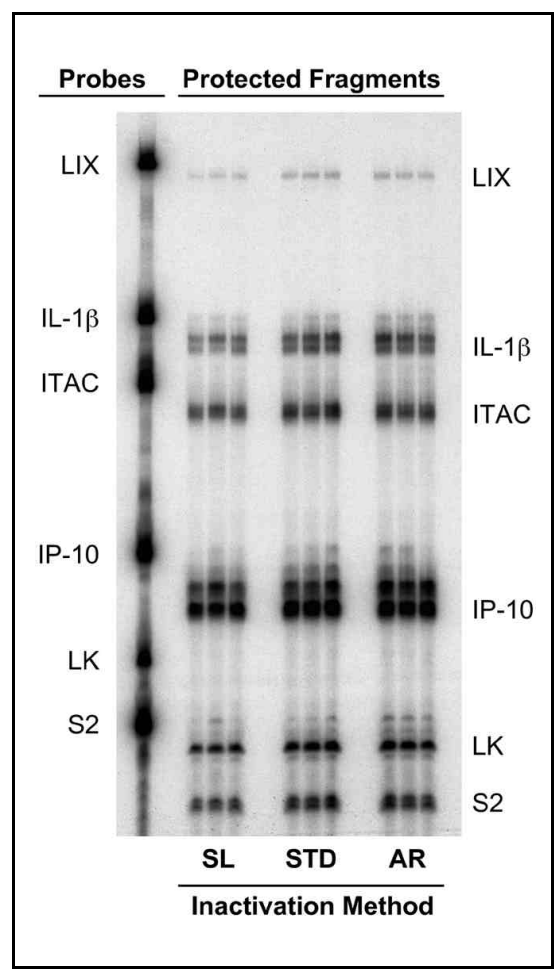

Figure 1. Autoradiogram of a representative experiment comparing three methods of RNase inactivation. Replicate RNA samples (three/method) were processed identically, except that RNase inactivation was performed using the streamlined (SL), standard (STD), or Ambion reagent (AR) methods, as described in the text.
The three inactivation methods produced qualitatively similar band patterns, with no evidence of sample degradation. There were no differences in the results for the individual probes (not shown), so the three inactivation methods were compared using the com bined data for all probes (Figure 2).
Omission of phenol:chloroform extraction resulted in a reduction in raw signal strength to $63 \% \pm 13 \%$ (mean $\pm \mathrm{SD}$ ) of the standard method (Figure 2A). How ever, the background signals were also reduced to $73 \% \pm 15 \%$ of standard (Figure $2 \mathrm{~B})$. This resulted in a signal-tobackground ratio for the streamlined
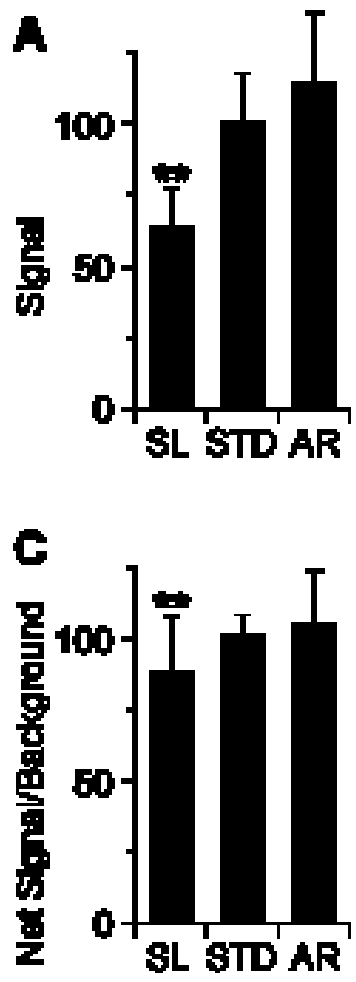

$\mathbf{E}$

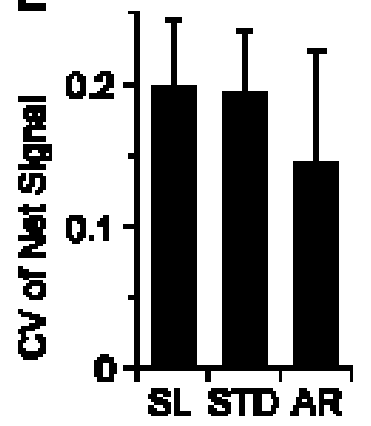

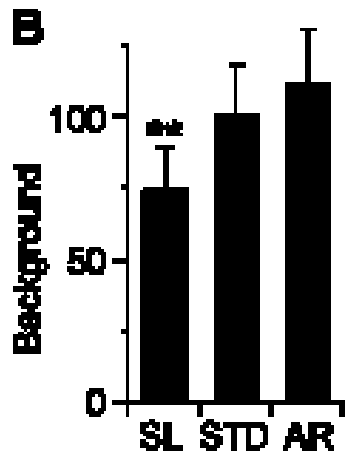
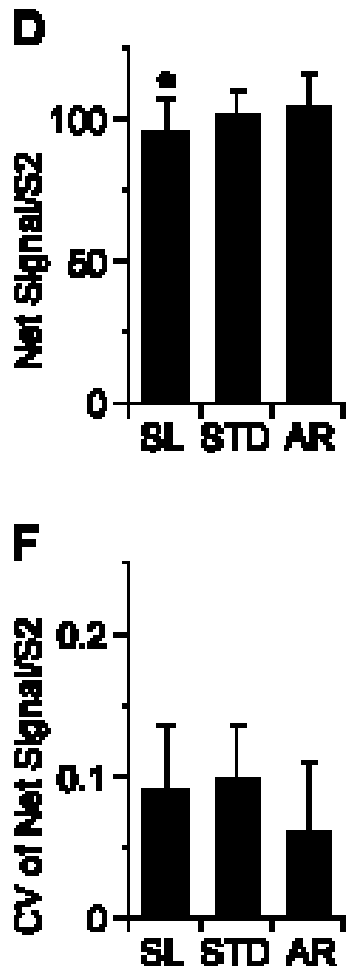

Figure 2. Quantitative comparison of RNase inactivation. Data for all probes in three separate experiments, using the streamlined (SL), standard (STD), and Ambion reagent (AR) methods, were normalized and analyzed as described in the text. The graphs show the group means and standard deviations. Signal intensities (A), background intensities (B), ratios of net signal to background (C), and ratios of net cytokine/chemokine signal to S2 (D) were scaled so that the mean value for the STD equaled 100. $P<$ 0.05 and $P<0.001$ versus STR and AR by Fisher's PLSD test. The different inactivation methods did not produce a statistically significant difference in $\mathrm{CV}$ for the net signals $(\mathrm{E})$ or in the $\mathrm{CV}$ for the ratio of net cytokine/chemokine signals to $\mathrm{S} 2$ (F) by ANOVA. 
method that averaged $87 \% \pm 19 \%$ of standard (Figure 2C). When signals for the individual chemokine and cytokine probes were normalized by the S2 signal in the same lane, results for the streamlined method were $94 \% \pm 12 \%$ of standard (Figure 2C). Because the limit of detection for weak signals is determined by the signal-to-background ratio (Figure $2 \mathrm{C}$ ), and not by the absolute signal (Figure 2A), we conclude that omission of the phenol:chloroform extraction step results in only a small (13\%) loss of sensitivity compared to the standard method. The signal-tobackground ratios of the standard and Ambion reagent methods did not differ.

To assess the reproducibility of the assay, we compared the $\mathrm{CV}$ for replicate samples. Omission of phenol:chloroform extraction did not affect the reproducibility of the assay compared to the standard method (Figure 2, E and F). For all three methods, the CV of signals normalized by S2 (Figure 2F) were about $50 \%$ of the CV of the non-normalized signals, indicating that about half of the between-sample variability in the RPA is a result of differences in loading.

Our results show that elimination of phenol:chloroform extraction following proteinase $\mathrm{K}$ digestion does not affect the reliability of our streamlined assay and produces only a small reduction in sensitivity (13\%) compared to the standard method. This small reduction in sensitivity is unlikely to have any practical significance for the vast majority of applications and can easily be compensated, if needed, by increasing the amount of RNA analyzed. For an experiment with 40 samples, our streamlined procedure saves about $2 \mathrm{~h}$ handson time compared with the standard procedure $(1 \mathrm{~h}$ from avoiding RNA sample reprecipitation, $1 \mathrm{~h}$ from omitting phenol:chloroform extraction). The reagents costs for the streamlined and standard protocols are essentially identical (about $\$ 0.23 /$ sample). The use of Ambion's inactivation/precipitation reagent would save an additional 10 min hands-on time but at current prices would increase the cost of the assay nearly 7 -fold, to $\$ 1.55 /$ sample. We conclude that our streamlined protocol provides a low-cost, reliable, time-efficient alternative that facilitates the routine use of the RPA for large numbers of samples. RNA stored in formamide can be used with no other change in established protocols, including those using nonradioactive labeling. However, we recommend that users test the effects of omitting phenol:chloroform extraction if their RPA conditions differ substantially from those described here.

\section{REFERENCES}

1.Bordonaro, M., C.F. Saccomanno, and J.L. Nordstrom. 1994. An improved T1/A ribonuclease protection assay. BioTechniques 16:428-430.

2.Chomczynski, P. 1992. Solubilization in formamide protects RNA from degradation. $\mathrm{Nu}-$ cleic Acids Res. 20:3791-3791.

3.Chomczynski, P. and N. Sacchi. 1987. Single-step method of RNA isolation by acid guanidinium thiocyanate-phenol-chloroform extraction. Anal. Biochem. 162:156-159.

4.Gilman, M. 1989. Ribonuclease protection assay. In F.M. Ausubel, R. Brent, R.E. Kingston, D.D. Moore, J.G. Seidman, J.A. Smith, and K. Struhl (Eds.), Current Protocols in Molecular Biology. John Wiley \& Sons, New York.

5.Harju, S. and K.R. Peterson. 2001. Sensitive ribonuclease protection assay employing glycogen as a carrier and a single inactivation/precipitation step. BioTechniques 30:1198-1204.

6.Hod, Y. 1992. A simplified ribonuclease protection assay. BioTechniques 13:852-854.

7.Mironov, V.N., M. Van Montagu, and D. Inzé. 1995. High throughput RNase protection assay. Nucleic Acids Res. 23:3359-3360.

8.Rossi, D.L., S.D. Hurst, Y. Xu, W. Wang, S. Menon, R.L. Coffman, and A. Zlotnik. 1999. Lungkine, a novel CXC chemokine, specifically expressed by lung bronchoepithelial cells. J. Immunol. 162:5490-5497.

9.Rovai, L.E., H.R. Herschman, and J.B. Smith. 1998. The murine neutrophil-chemoattractant chemokines LIX, KC, and MIP-2 have distinct induction kinetics, tissue distributions, and tissue-specific sensitivities to glucocorticoid regulation in endotoxemia. J. Leukoc. Biol. 64:494-502.

10.Saccomanno, C.F., M. Bordonaro, J.S. Chen, and J.L. Nordstrom. 1992. A faster ribonuclease protection assay. BioTechniques 13:846-850.

11.Sambrook, J., E.F. Fritsch, and T. Maniatis. 1989. Molecular Cloning: A Laboratory Manual. CSH Laboratory Press, Cold Spring Harbor, NY.

12.Smith, J.B. and H.R. Herschman. 1995. Glucocorticoid-attenuated response genes encode intercellular mediators, including a new C-XC chemokine. J. Biol. Chem. 270:1675616765 .

13. Vanguri, P. and J.M. Farber. 1990. Identification of CRG-2. An interferon-inducible mRNA predicted to encode a murine monokine. J. Biol. Chem. 265:15049-15057.

14.Widney, D.P., Y.R. Xia, A.J. Lusis, and J.B. Smith. 2000. The murine chemokine CXCL11 (IFN-inducible T cell $\alpha$ chemoattractant) is an IFN- $\boldsymbol{\gamma}$ - and lipopolysaccharide-inducible glucocorticoid-attenuated response gene expressed in lung and other tissues during endotoxemia. J. Immunol. 164:6322-6331.

15. Wilfinger, W.W., K. Mackey, and P. Chom czynski. 1997. Effect of pH and ionic strength on the spectrophotometric assessment of nucleic acid purity. BioTechniques 22:474-481.

This work was supported, in part, by National Heart, Lung, and Blood Institute grant no. HL57008 to J.B.S. Address correspondence to Dr. Jeffrey B. Smith, Pediatrics/Neonatology, UCLA School of Medicine, Center for the Health Sciences B2-325, 10833 Le Conte Avenue, Los Angeles, CA 90095, USA. e-mail: jbsmith@ ucla.edu

Received 14 September 2001; accepted 21 December 2001.
Tam Thuan Nguyen and Jeffrey B. Smith UCLA School of Medicine Los Angeles, CA, USA 